\title{
EFFECTIVENESS OF KINESIOLOGICAL TAPE IN MYOFASCIAL PAIN SYNDROME OF GASTROCNEMIUS MUSCLE
}

\author{
Riffat Asghar Gill, Muhammad Salman Bashir*, Kehkshan Khalid**, Naveed Anwar \\ National Cricket Academy Islamabad Pakistan, *Riphah International University Islamabad Pakistan, **Imperial College of Business Studies Lahore Pakistan,
}

\begin{abstract}
Objective: To see the effectiveness of kinesiological tape in myofascial pain syndrome of gastrocnemius muscle for the early recovery after injury and thus increase functional outcome.

Study Design: Quasi-experimental study.

Place and Duration of Study: National cricket academy Lahore and Sports and Spine Professional's Clinic, Defense Phase-IV Lahore Pakistan, from Aug 2017 to Oct 2017.

Methodology: Consecutive sampling technique was used to enrol the patients of myofascial pain syndrome based on the predefined inclusion and exclusion criteria. Patients were selected and the kinesiological tape was applied thrice a week for two consecutive weeks. the patient was then re-evaluated after every two days of previous kinesiological tape application in terms of the visual Analogue Scale.

Results: It was observed that kinesiological tape had a significant effect on pain reduction of the myofascial pain syndrome of the gastrocnemius muscle $(p<0.001)$. There was a significant reduction of pain level after application of Kinesio tape till 4 th application with pre-treatment means $6.70 \pm 1.45$ that was reduced to $2.98 \pm 2.24$ in post-treatment $(p<0.05)$. In addition, there was no significant reduction of pain between the $5^{\text {th }}$ and $6^{\text {th }}$ application with mean for the 6 th session as $2.96 \pm 2.27(p>0.05)$.

Conclusion: The Kinesiological tape has a significant effect on pain reduction of gastrocnemius muscle suffering from myofascial pain syndrome. The application of kinesiological tape has maximum effect up to its $4^{\text {th }}$ application. After $5^{\text {th }}$ session of taping, the effect was almost constant.
\end{abstract}

Keywords: Athletic tape, Myofascial pain syndromes, Muscle, Pain, Treatment outcome.

How to Cite This Article: Gill RA, Bashir MS, Khalid K, Anwar N. Effectiveness of Kinesiological tape in Myofascial Pain Syndrome of Gastrocnemius Muscle. Pak Armed Forces Med J 2021; 71(5): 1666-1668. doi: https://doi.org/10.51253/pafmj.v71i5.3327

This is an Open Access article distributed under the terms of the Creative Commons Attribution License (https://creativecommons.org/licenses/by-nc/4.0/), which permits unrestricted use, distribution, and reproduction in any medium provided the original work is properly cited.

\section{INTRODUCTION}

Myofascial pain syndrome, ${ }^{1}$ is a term that is used to describe that painful sensation that runs along with a skeletal muscle group and its fascia The patient presents with constant pain and aching muscles. ${ }^{2,3} \mathrm{~A}$ clinical review of the patients having myofascial pain syndrome demonstrate that these patients have firm bands in skeletal muscles, a hyperesthetic area in their band known as trigger point, from which pain referred. ${ }^{1}$ Abnormal posture, in which undue stress is placed on skeletal muscles, ${ }^{4}$ emotional, ${ }^{5}$ and job-related factors are important contributing factors. ${ }^{6}$ Dr. Kenzo Kase was the first who designed Kinesiological tape in Japan 30 years ago and then in 1990.7 There is a paper attached on the back of the tape which can be folded, removed and torn in different ways based on the desired application of tape and thus makes its use much easier. 8,9 The thickness of the tape is the same as the epidermis of the skin, that's why the body does not

Correspondence: Dr Riffat Asghar Gill, National Cricket Academy Islamabad Pakistan

Received: 02 Oct 2019; revision received: 13 Feb 2021; accepted: 17 Feb 2021 perceive its weight when KT is properly applied according to the contours of the body. It is composed of $100 \%$ cotton and polymer elastic strands which mimic the qualities of fingerprints on fingertips. ${ }^{4} \mathrm{KT}$ works by lifting the skin from the underlying fascia which enhances the oxygen supply to muscles, decrease inflammation and increase anaerobic as well as the aerobic capacity of muscle. 8,10 This study focused on the effect of Kinesio tape in myofascial pain syndrome of gastrocnemius muscle as it is the commonest muscle affected in female athletes. This would be effective for females that encounter such issues and continue with agony into chronic issues. There is a dire need to find an effective way to reduce pain in a short period for gastrocnemius pain issues.

\section{METHODOLOGY}

The quasi experimental study design was used and data was collected from National Cricket Academy Lahore and sports and spine Professionals clinic, Defense Lahore. Study was completed in 3 months from August to October 2017. Consecutive sampling was used to get the sample. 
Inclusion Criteria: Female patients who presented with myofascial pain syndrome of gastro-cnemius muscle within the age of 18-40.

Exclusion Criteria: Female patient suffering from any kind of skin disease, spinal cord compression, developmental deformity of lower limb, any previous surgery of tibia and fibulae and pre-existing endocrine disorder or inflammatory condition were excluded from the study.

A total of 54 sample size was calculated using mean and standard deviation $4.3 \pm 0.9$ before treatment (no kinesiological tape application) and $3.2 \pm 1.0$ after treatment (kinesiological tape application), ${ }^{11}$ and taking 95\% confidence interval and 5 percent margin of error and power of study is 0.80 . Sample size was calculated through $\mathrm{G}^{*}$ power software. Ethical approval was taken from ethical review board of Riphah International University, Lahore (Ref. \# RCR \& AHS/REC/ PP-DPT/S14/002). Patients pain marked on scale from 0 (no pain) to 10 (sever pain) for daily functions before and after completion of treatment as measured VAS. The visual analogue scale was used for assessment. The pain of gastrocnemius muscle was scored according to VAS before application of kinesiological tape. Measure the tape from the bottom to top of the calf. Cut 2 long I STRIPs and 1 short I STRIP. Round the edges to prevent them catching on clothing. Rip the ends of the long strip and lay the base of the strip down with $30 \%$ stretch at the top of the Achilles on affected side. ${ }^{12}$ These patients were treated with KT thrice a week for 2 consecutive weeks. The post treatment pain level was also accessed through VAS. The data was analyzed by using the Statistical Package for Social Sciences (SPSS) version 23. Normality of data was assessed by kolmogorov smirnov test. Data was found to be normally distributed. The mean differences with SD for the outcome measures of pain of gastrocnemius muscles was calculated for baseline and after every session till $6^{\text {th }}$ session. Repeated measure ANOVA test was used to find out the difference between VAS score of baseline and 6 post treatment assessments. The $p$ value $\leq 0.05$ was considered significant.

\section{RESULTS}

The mean age of participants was $28.55 \pm 6.03$ years while mean height and weight were $1.64 \pm 0.14 \mathrm{~m}$ and $63.31 \pm 11.83 \mathrm{~kg}$ respectively. After analysis, it was observed that kinesiological tape has a significant effect on pain reduction of the myofascial pain syndrome of the gastrocnemius muscle $(p<0.001)$ shown in Table-I. There was a significant reduction of pain level after application of Kinesio tape till 4th application with pre-treatment means $6.70 \pm 1.45$ that is reduced to $2.98 \pm 2.24$ in post-treatment. And there was no significant reduction of pain between the $4^{\text {th }}$ and $5^{\text {th }}$ and then $5^{\text {th }}$ and $6^{\text {th }}$ session as $p$-value are $>0.05$ as shown in Table II. So kinesiological tape is effective in pain reduction of the myofascial pain syndrome of gastrocnemius muscle as there is a significant difference in mean after the first and 6th session. So it is concluded that kinesiological tape is effective in pain reduction of the myofascial pain syndrome of gastrocnemius muscle.

Table-I: Comparison of visual analog scale of difference sessions.

\begin{tabular}{l|c|c|c|c|c|c|c}
\hline Sessions & $\mathbf{1}^{\text {st }}$ & $\mathbf{2}^{\text {nd }}$ & $\mathbf{3}^{\text {rd }}$ & $\mathbf{4}^{\text {th }}$ & $\mathbf{5}^{\text {th }}$ & $\mathbf{6}^{\text {th }}$ & $\boldsymbol{p}_{\text {-value }}$ \\
\hline Visual & $5.53 \pm$ & $4.46 \pm$ & $3.48 \pm$ & $3.12 \pm$ & $2.98 \pm$ & $2.96 \pm$ & \\
Analog & 1.67 & 1.87 & 2.11 & 2.21 & 2.24 & 2.26 & $<0.001$ \\
Scale (pain) & & & & & \\
\hline
\end{tabular}

Table-II: Inter group comparison of session.

\begin{tabular}{|c|c|c|c|c|c|c|}
\hline $\begin{array}{l}\text { Session-wise } \\
\text { Comparison }\end{array}$ & $\begin{array}{c}1^{\text {st }} \\
\& 2^{\text {nd }}\end{array}$ & $\begin{array}{c}2^{\text {nd }} \\
\& 3^{\text {rd }}\end{array}$ & $\begin{array}{l}3^{\text {rd }} \\
\& 4^{\text {th }}\end{array}$ & $\begin{array}{l}4^{\text {th }} \\
\& 5^{\text {th }}\end{array}$ & $\begin{array}{l}5^{\text {th }} \\
\& 6^{\text {th }}\end{array}$ & $\begin{array}{l}1^{\text {st }} \\
\& 6^{\text {th }}\end{array}$ \\
\hline $\begin{array}{l}\text { Visu } \\
\text { Scal }\end{array}$ & $<0.001$ & $<0.00$ & 0.00 & 0.1 & 1.00 & $<0.001$ \\
\hline
\end{tabular}

\section{DISCUSSION}

In the literature review, a comparative study on Kinesio tape (KT) and McConnell tape (MT) was done to see the effect of anterior knee pain during functional activities was observed. The pain was observed during squat lifting and stair climbing in terms of the visual analogue scale. The result of this study concluded that both KT and MT is helpful in pain reduction during stair climbing activities. ${ }^{13}$ Similar results were seen in another study done by Ozturl et al. and pain was reduced significantly. ${ }^{14}$ The result of our study was coinciding with this study in which Kinesio tapping is helpful in the management of myofascial pain syndrome.

An interventional study was done by Tsal et al, to see the effect of Kinesio tape in comparison with conventional physiotherapy treatment for treating planter fasciitis. Results were measured by the pain description score and foot functional score and by ultrasonography assessment. It revealed that $\mathrm{KT}$ along with other physiotherapeutic techniques is helpful in alleviating pain better than traditional physical therapy plans alone. But in current study the effect of KT alone, instead of with other physiotherapy techniques is seen in markable pain reduction after it applies for two consecutive weeks. ${ }^{15,16}$

An interventional study was done to see the effectiveness of Kinesio tape on quality of life, pain, 
oedema, range of motion (ROM) and myoelectric activity on postmenopausal women having chronic venous insufficiency. It was observed that KT does not help improve quality of life, oedema and range of motion although it may decrease venous symptoms, pain and their severity. ${ }^{17}$ However, in the current study it is declared KT is helpful in the reduction of pain and thus the patient feels easy in ADL's.

A randomized clinical trial was done to see the short term effect of Kinesio tape on cervical range of motion and pain. It was statistically approved that when Kinesio tape is applied with proper stretch and tension, it produces improvement immediately and after 24 hours follow up. But this improvement in pain and range of motion (ROM) was of short duration and not clinically significant. ${ }^{18}$ However, in this research significant improvement is seen in pain reduction when applied to the gastrocnemius muscle. Therefore, ki-Kinesiotaping can help treat musculoskeletal conditions.

Numerous studies have been conducted by various researchers on the effectiveness of kinesiological tape with different aspects and little researchers were done for pain reduction of the myofascial pain syndrome of gastrocnemius muscle. This article helps predict that Kinesio taping is very effective in treating gastrocnemius muscle-related myofascial pain.

\section{LIMITATION OF STUDY}

Availability of kinesiology tape was difficult. Kinesio tape was costly and follow up of the patients up to the 6th application of KT was difficult.

\section{RECOMMENDATIONS}

Further research should be done to see the effectiveness of kinesiological tape in increasing muscular strength and functional outcome after its application.

\section{CONCLUSION}

The Kinesiological tape has a significant effect on pain reduction of gastrocnemius muscle suffering from myofascial pain syndrome. The application of kinesiological tape has maximum effect up to its 5th application. After the 5th application, the effect will be constant.

\section{Conflict of Interest: None.}

\section{Authors' Contribution}

RAG: Direct contribution, MSB: Supervision, KK: Intellectual contribution, NA: Intellectual contribution.

\section{REFERENCES}

1. Ay S, Konak HE, Evcik D, Kibar S. The effectiveness of Kinesio Taping on pain and disability in the cervical myofascial pain syndrome. Rev Bras Reumatol Engl Ed 2017; 57(2): 93-99.
2. Nielsen C, Pluhar G. Diagnosis and treatment of hind limb muscle strain injuries in 22 dogs. Vet Comp Orthop Traumatol 2005; 18(4): 247-252.

3. Zhang XF, Liu L, Wang BB, Liu X. Evidence for Kinesio taping in management of myofascial pain syndrome: a systematic review and meta-analysis. Clin Rehabil 2019; 33(5): 865-874.

4. Fricton JR. Myofascial pain syndrome. Neurol Clin 1989; 7(2): 413-27.

5. Sun A, Yeo HG, Kim TU, Hyun JK, Kim JY. Radiologic Assessment of Forward Head Posture and Its Relation to Myofascial Pain Syndrome. Ann Rehabil Med 2014; 38(6): 821-826.

6. Yin L, Wang L. acute effect of kinesiology taping on postural stability in individuals with unilateral chronic ankle instability. Front Physiol 2020; 11(2): 192-198.

7. Williams S, Whatman C, Hume PA, Sheerin K. Kinesio taping in treatment and prevention of sports injuries: a meta-analysis of the evidence for its effectiveness. Int J Sports Med 2012; 42(2): 153-164.

8. Van der Westhuizen JH. The relative effectiveness of Kinesiotape versus dry needling in patients with a myofascial pain syndrome of the trapezius muscle 2012, [Internet] Available at: https:// openscholar.dut.ac.za/handle/10321/732 (Accessed on October 15, 2017)

9. Lietz-Kijak D, Kopacz L, Ardan R, Grzegocka M, Kijak E. Assessment of the short-term effectiveness of kinesiotaping and trigger points release used in functional disorders of the masticatory muscles. Pain Res Manag 2018; 2018(2): 5464985.

10. Abdelfattah A, Kattabei O, Nasef S, Semaya A. Effect of Kinesio tape in myofascial pain syndrome 'Randomized Control Trial'. J Physiother 2016; 102(1): e140.

11. Faul F, Erdfelder E, Lang A-G, Buchner A. G*Power 3: A flexible statistical power analysis program for the social, behavioural, and biomedical sciences. Behav Res Method 2007; 39(2): 175-191.

12. Sahar B, Mohammad Ali S, Ali A, Ismail Ebrahimi T. Effect of Gastrocnemius Kinesio Taping on Countermovement Jump Performance and Vertical Stiffness Following Muscle Fatigue. J Sport Rehabil 2018; 27(4): 306-311.

13. Campolo M, Babu J, Dmochowska K, Scariah S, Varughese J. A comparison of two taping techniques (Kinesio and McConnell) and their effect on anterior knee pain during functional activities. Int J Sports Phys Ther 2013; 8(2): 105-109.

14. Öztürk G, Külcü DG, Messi N, Şilte AD, Aydog E. Efficacy of Kinesio tape application on pain and muscle strength in patients with myofascial pain syndrome: a placebo-controlled trial. J Phys Ther Sci 2016; 28(4): 1074-1079.

15. Tsai CT, Chang WD, Effects of short-term treatment with kinesiotaping for plantar fasciitis. J Musculoskelet Pain 2010; 18: 71-80.

16. Prange GB, Kottink AI, Buurke JH, Eckhardt MM, van KeulenRouweler BJ, Ribbers GM, et al. The effect of arm support combined with rehabilitation games on upper-extremity function in subacute stroke: a randomized controlled trial. Neurorehabil Neural 2015; 29(2): 174-182.

17. Aguilar-Ferrándiz ME, Castro-Sánchez AM, Matarán-Peñarrocha GA, García-Muro F, Serge T. Effects of kinesio taping on venous symptoms, bioelectrical activity of the gastrocnemius muscle, range of ankle motion, and quality of life in postmenopausal women with chronic venous insufficiency: a randomized controlled trial. Arch Phys Med Rehabil 2013; 94(12): 2315-2328.

18. Chang WL, Shih YF, Kao MJ, Chen WY, Chen JP. Short-term effects of cervical kinesio taping on pain and cervical range of motion in patients with acute neck pain: a randomized clinical trial. Phy Therap 2014; 39(4): 231-239. 